\title{
Respiratory disease caused by synthetic fibres: a new occupational disease ${ }^{1}$
}

\author{
J. CORTEZ PIMENTEL, RAMIROA VILA, \\ and A. GA L V Ã L OURE NÇO \\ IANT (Department of Pathology of Sanatorio D. Carlos I), Institute of Pathology and \\ Department of Chest Diseases, Lisbon University Faculty of Medicine
}

\begin{abstract}
Pimentel, J. C., Avila, R., and Lourenço, A. G. (1975). Thorax, 30, 204-219. Respiratory disease caused by synthetic fibres: a new occupational disease. Seven patients exposed to the inhalation of synthetic fibres presented with various bronchopulmonary diseases, such as asthma, extrinsic allergic alveolitis, chronic bronchitis with bronchiectasis, spontaneous pneumothorax, and chronic pneumonia. The histological features are described and an attempt has been made to set up immunological techniques for the diagnosis. A series of histochemical techniques, based on textile chemistry, are proposed for the identification of the inclusions found in bronchopulmonary lesions. The results of the experimental production of the disease in guinea-pigs by the inhalation of synthetic fibre dusts are presented. The prognosis of these cases is good in the acute or recently established cases but is poor when widespread and irreversible fibrosis has set in. The authors consider that pulmonary disease due to inhaled particles is probably set off by an individual factor, possibly immunological.
\end{abstract}

Synthetic fibres, on the market since the last war, have revolutionized industry, particularly the textile industry.

Fibres produced by chemical synthesis may be grouped into a small number of categories according to their nature, chemical structure, and textile characteristics. At present nylon, polyester, polyurethane, polyolefine, polyacrylonitrile (acrylic fibres), and other vinyl-type polymer fibres are produced in industry, nylon being the most popular.

The attention of the factory physician in the textile industry is still centred mainly on byssinosis, and very few studies are available on the effects of synthetic fibres. Tiller and Schilling (1958) state that there are no changes like those of byssinosis in workers exposed to nylon dust. Simonin (1961) reported irritation of the mucous membranes, bronchial asthma and burns in the nylon industry, produced by the phthalic anhydride used in its production, and also hypersensitivity dermatitis due to repeated and prolonged contact with nylon.

${ }^{1}$ This study was subsidized by the Instituto de Alta Cultura (Project LMC5)
Sano (1967) called attention to the fact that inhalation of nylon dust, in a series of cases of pneumoconiosis due to organic dusts, can give rise to fibrotic nodules in the lung. Finally, A and Ishikawa (1967) also described animal expenments in which different types of dust, including synthetics, were instilled into the trachea, agd noted that the suspensions containing nylon produced 'alveolar-type foci in the lungs'.

In 1968 a lung biopsy from a worker in the textile industry who worked with wool and acrylic (Orlon) fibres was examined. She possented an asthma-like syndrome resistant therapy. The lesions involved the interalveolft septa and were closely related to a fibrillar 'foreign material' that was suspected of bei wool or Orlon fibres. An attempt to prove this was made by comparing samples of both fibres with the inclusions found within the lesions in lung. The lack of birefringence on polarized lig伍 $t$ microscopy and the negativity of the performicacid alcian-blue stain for keratin in the foreigh material in the lung excluded the possibility of being wool. Insufficient histochemical means existed for the identification of Orlon fibres (Pearse, 1968). 
The present study was undertaken in an attempt to understand this case and the larger problem it presented. The various clinicopathological forms of pulmonary change found in workers exposed to the inhalation of synthetic fibres are presented.

These conditions, diagnosed as tuberculosis or merely ignored, can be recognized by identification of the synthetic materials in the lesions by histophysical and histochemical methods based on the findings of textile chemistry. The lung lesions responsible for the clinical conditions have been reproduced experimentally. Immunological techniques have been used in an attempt to diagnose these conditions.

\section{MATERIAL AND METHOD}

1. Clinical, radiological, laboratory, and pathological studies were undertaken of seven cases chosen because:

they occurred in workers in the textile industry who manipulated synthetic fibres, or workers who made clothes from synthetic fabrics;

their lung changes differed from one another;

it was impossible to establish an aetiological diagnosis, particularly tuberculosis;

it was impossible to identify foreign matter that might correspond to textile fibres by standard microscopy.

2. Detailed knowledge of the work of the patient was sought, together with characterization of the various types of fibres to which he was exposed, duration of exposure, time of appearance of the first symptoms, and the course of the lesions after identification.

3. Samples of the various textile fibres and of the dust to which the patient was professionally exposed were examined. These samples were studied as fresh preparations and in paraffin sections.

Special care was taken with the mounting substance because these particles are usually colourless and transparent. Following norms used in textile chemistry (The Textile Institute, 1970), media with the most adequate refraction index were chosen-liquid paraffin for all types of fibres and glycerin jelly for cotton fibres. The current methods of textile fibre identification (Koch, 1963; Algerino, 1969) were adapted for histophysical and histochemical examination as no appropriate methods were available for the characterization of the fine particles of synthetic material contained in the dust collected from the workers.

The Table summarizes the more important solubility and staining reactions used in textile chemistry laboratories (Koch, 1963) that can be employed as efficiently in tissue chemistry. The results were observed with low magnification of the optic microscope and photographed in black and white and in colour for more detailed analysis. Some reactions were performed, according to textile chemical treatises, after the reagents had been submitted to the required temperature. Conventional, polarized light, phase

TA BLE

HISTOCHEMICAL AND HISTOPHYSICAL METHODS OF IDENTIFICATION OF TEXTILE FIBRES USED IN THIS STUDY

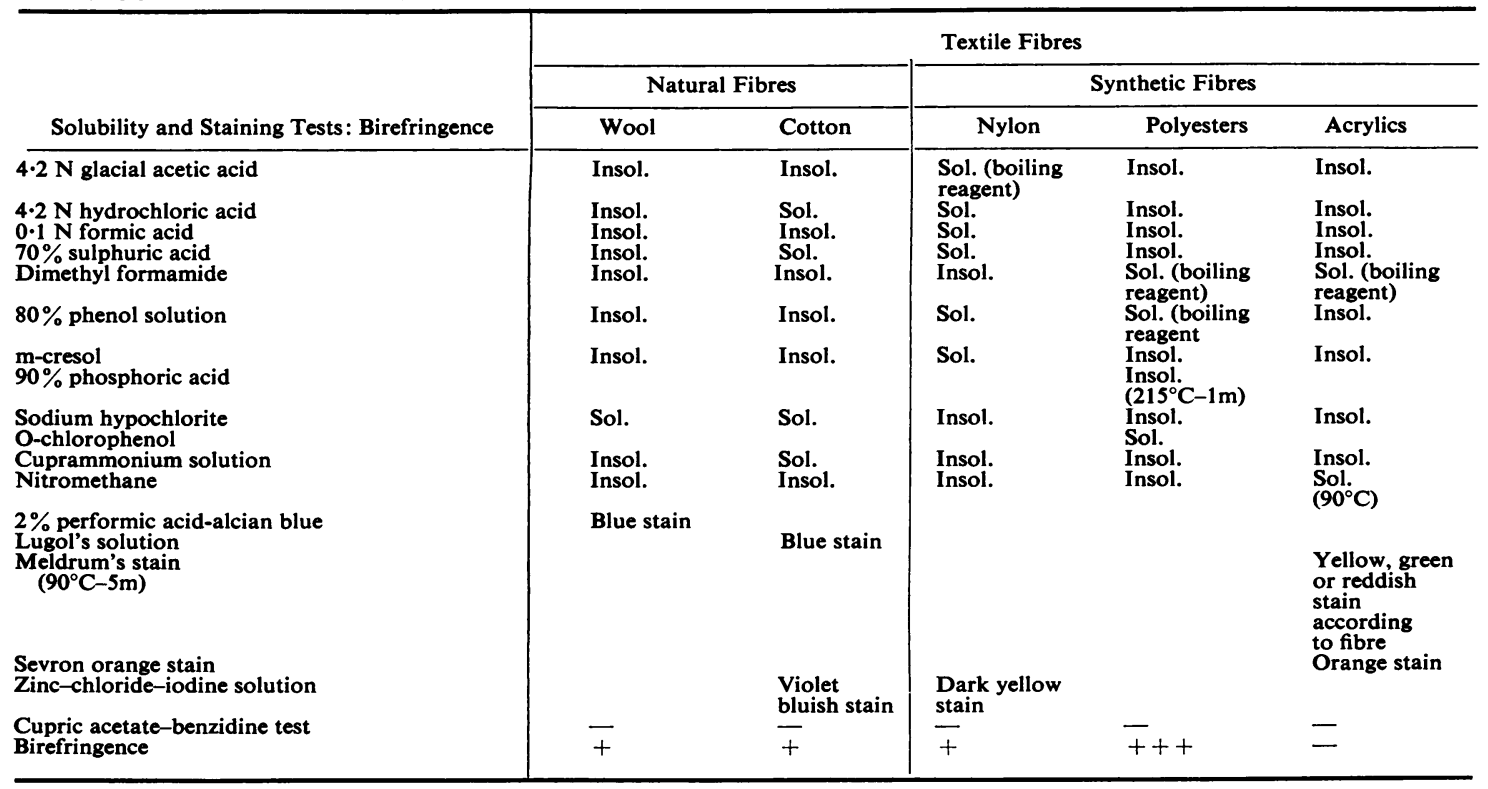


contrast, and interference microscopes were used in these examinations.

4. Specimens of lung obtained by transbronchial, transthoracic, and surgical biopsies and necropsy were examined histologically.

Paraffin sections were stained with haematoxylineosin, PAS, reticulin, collagen, elastic tissue, fungus, acid-fast, and calcium stains. The techniques for identification of dust particles mentioned above were applied to the lung sections, an attempt being made to be as exact as possible with the results of the solubility tests, reading them with a polarized microscope when birefringent fibres were involved-nylon, polyester, wool, and cotton-or a phase contrast microscope when not birefringent-acrylic dusts.

5. Immunological studies to demonstrate circulating precipitating antibodies were undertaken in two patients exposed to synthetic fibres and wool and presenting respiratory changes similar to the other cases described, and in 25 blood donors who served as controls.

Wool antigen was prepared by the thioglycolic acid technique described by Goddard and Michaelis (1934). Antigens of nylon, polyester, and a mixture of wool and polyester were prepared by a technique of Coca extraction, filtration, dialysis, and freeze-drying (Pimentel and Avila, 1973).

Ultrasonic disintegration of polyester and nylon was carried out to obtain a fine dust for future use.

The freeze-dried material was suspended in normal saline solution in concentrations of $20,30,50,60$, and $80 \mathrm{mg} / \mathrm{ml}$ for double diffusion tests with the patients and the control sera.

The various antigens obtained were suspended in human albumin in the same concentrations, and this suspension and the patient's serum were placed in $1.5 \mathrm{~mm}$ diameter wells, $5 \mathrm{~mm}$ apart on microscope slides, according to Culliford (1964). Electrophoresis was done for 30 minutes with a constant $42.5 \mathrm{~mA}$ current, after which the slides were washed, dried, and stained with Amidoschwartz 10B (Avila, 1968).

Skin sensitivity tests were done by the prick method on the two patients with Bencard wool and synthetic fibre antigens and with the ultrasonically disintegrated polyester and nylon dust suspended in neutral olive oil in concentrations of $1,5,10$, and $20 \mathrm{mg} / \mathrm{ml}$.

In patients who had bouts of sneezing, nasal obstruction, and rhinorrhoea, a few drops of suspension were placed in each nostril as a provocation test.

6. The lung changes in 28 guinea-pigs exposed to nylon dust and in 10 exposed to acrylic fibres (Orlon) were studied. The animals were placed in poorly ventilated cages and exposed to nylon and Orlon dusts administered by manual pulverizers in doses of $2 \mathrm{~g}$ three times a day, producing high dust concentrations. In each of these two series of experiments three controls were used. All animals were radiographed at the beginning and at the end of the experiments which lasted 325 days. Histological examination was made on 22 animals sacrificed at the end of the experiments and on six that died, of no apparent cause, $48,88,127,192,210$, and 230 da赝 after the beginning of the exposure. Routine histological methods and the histochemical techniques described for synthetic fibres were used as in th patients exposed to nylon and acrylic fibres.

CASE REPORTS AND SUPPLEMENTARY OBSERVATION@

CASE 1 A 27-year-old woman had worked for sid years in a textile factory where she was exposed to wool and acrylic fibres (Orlon). One year latep spells of sneezing set in with nasal obstruction and rhinorrhoea. Some months later asthma-like a tacks occurred, becoming progressively mof frequent and severe. Between attacks she had aip irritating cough, wheezing, and slight breathlesత్ర ness. Auscultation showed diffuse bronchial signs. There were increased lung markings on radiography. A haemogram, proteinogram, and sedimentation rate were normal. Respiratory function tests revealed a moderate degree of airwaȳs obstruction and slight reduction in the transfer factor. Bronchial biopsy showed goblet-cell hypeyplasia with thickening of the basal membraiv and a marked eosinophilic infiltration of the mucosa and submucosa as well as granulomata of histiocytes around fibrillar inclusions. Trangebronchial lung biopsy demonstrated a diffuse thickening of the interalveolar septa, partly dueㅡㄹ to reticulin and collagen fibres and partly cellular proliferation with granulomata, mađe up of histiocytes and fibroblasts (Fig. 1). A d tailed examination of the septal lesions showed that both in the granulomatous lesions and in the sclerotic areas there were small, irregularly placed slits. Some of these slits were empty, others contained small inclusions of fibrillar structume seen with phase contrast (Fig. 2) and interference microscopy but not showing birefringence wigh polarized light. Physical and chemical study of samples of dusts from the patient's environment and of the fibres which she encountered histochemical studies of the fibrillar 'inclusions? in the lung lesions showed that all the reactions considered characteristic of acrylic fibres weice positive. After leaving hospital the patient did no return to her former work. When seen a week after discharge she had had no further attacks of asthma although an irritating cough persisteg. A chest radiograph and pulmonary function tes?s remained unchanged.

CASE 2 A 27-year-old female textile worker ha् been exposed to cotton and polyester (Terylen for the past 11 years. She had had fatigue for the last three years, especially on returning horfe 


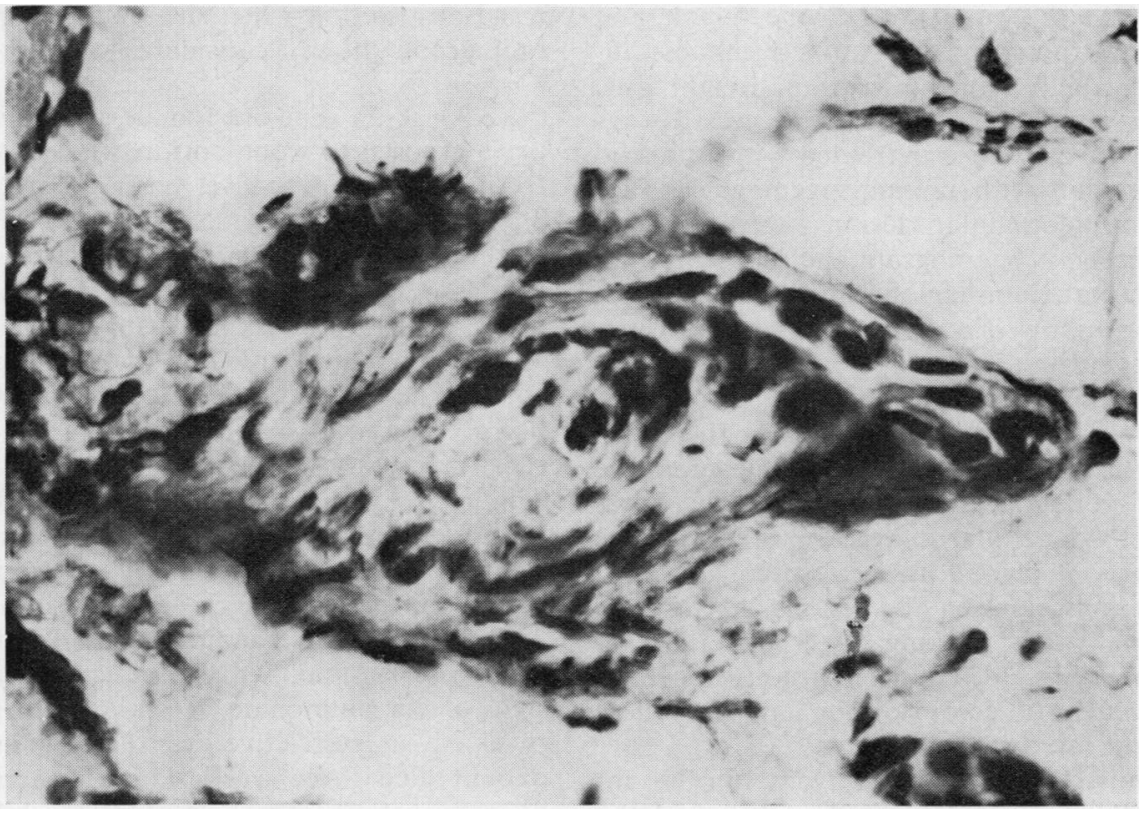

FIG. 1. Case 1. Detail of granuloma of the interalveolar septa. Cellular proliferation made up of histiocytes and fibroblasts. Note the presence of slits where the Orlon fibres lay $(H$ and $E \times 550)$.

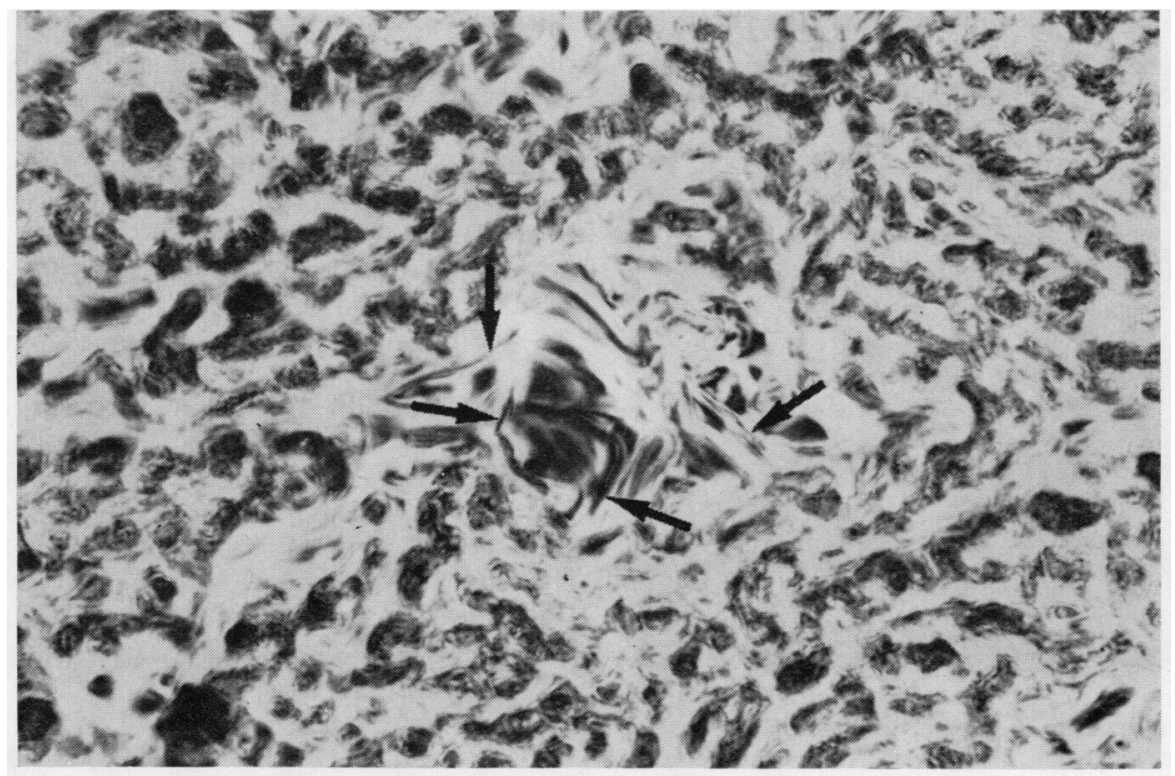

FIG. 2. Case 1. Detail of a granuloma of the interalveolar septa (phase contrast). Arrows show Orlon fibres. ( $H$ and $E \times 500$ ). 
from work. At this time she became hoarse and had nasal obstruction. Meanwhile weakness increased and cough, mucoid sputum, weight loss, and malaise set in. Her temperature was always normal. For a year she was treated with isoniazid and streptomycin with no improvement. Diffuse bilateral, reticulonodular lesions were present radiographically. A haemogram and sedimentation rate were normal; gammaglobulins were increased. Bronchoscopy showed no changes and lung function tests revealed a restrictive ventilatory defect with hypoxaemia and hypocapnia.

Lung biopsy showed focal lesions in the interalveolar septa that were thickened by oedema, the presence of reticular and a few collagen fibres and, especially, a cellular infiltration of histiocytes and fibroblasts. Polarized light microscopy showed birefringent inclusions in the lesions, partly as a fine dust and partly as long fibres, generally in small bundles (Fig. 3). These inclusions appeared as small bundles of colourless or slightly yellow fibres on light microscopy.

Histochemistry of the birefringent fibrillar inclusions in the lesions showed that they had the characteristics of the polyesters (Fig. 4). The patient was advised to change her job; one year later there was considerable improvement and all she complained of was an irritating cough and

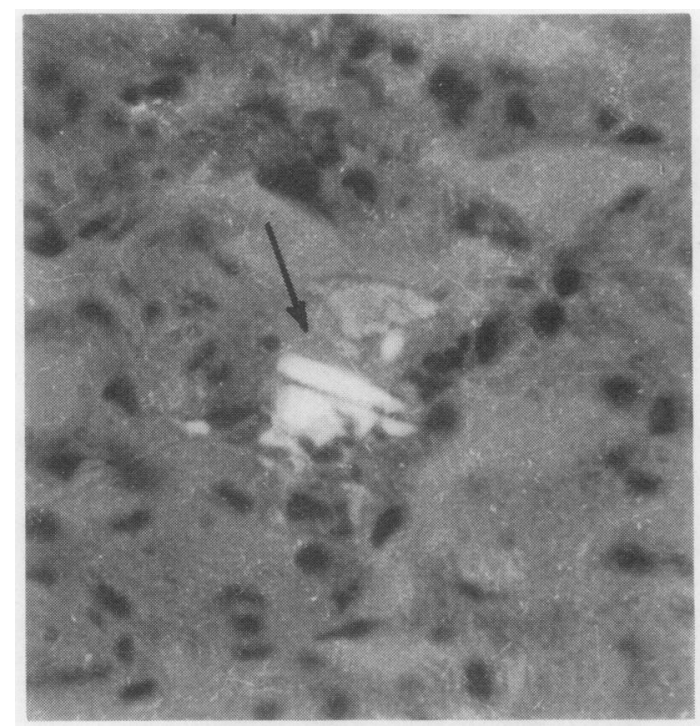

FIG. 3. Case 2. Lesions of the interalveolar septa (polarized light). Bundles of birefringent fibres correspond to a polyester (Terylene). Note that the appearances are the same as that of a sample of this material (Fig. 4) ( $H$ and $E \times 380)$. nasal obstruction when she 'caught cold'. A chet radiograph showed considerable improvement. $\stackrel{\text { ? }}{+}$

CASE 3 A 54-year-old female textile worker hisd been exposed to wool, cotton, and synthetic fibis from age 25 up to five years before her dea禹. She was admitted to Santa Maria Hospital gin December 1965 complaining of progressive breathlessness on exertion over the past eight years, which had now become permanent even at rest. A year previously an acute episode had led to her admission to another hospital. One week before her present admission a similar episode had occispred. Auscultation revealed crackles at both basks. The liver was slightly enlarged. Ankle oedema aigd cyanosis were present. A chest radiograph showed right ventricular enlargement and reticular in trations at the periphery of both lungs with some honeycombing. A haemogram and sedimentation rate were normal. An electrocardiogram showed signs of cor pulmonale. Respiratory function tests revealed a restrictive ventilatory defect. Tate patient died three weeks later. The pathological diagnosis at necropsy was 'diffuse, bilateral p@monary fibrosis with honeycomb lungs, sevepe arteriosclerosis of the branches of the pulmonaty arteries, hypertrophy and dilatation of the rigit ventricle and auricle'. Microscopic examination of the lungs showed diffuse fibrosis with preservation of lung structure in some areas while in others the alveoli were completely obliterated by large sheets of scar tissue. This fibrosis was also prominent around the bronchi and small blood vessels a under the pleura, where it formed a wide plaqge of sclerosis (Fig. 5) corresponding to the area of greater density on the radiograph. In less affected areas the septa were thickened by reticulin fibres, histiocytes, and fibroblasts. In some areas the alveoli were reduced to slits and the epithelium was swollen, showing a glandular-like appearance. In addition emphysema and honeycombing wefe present (Fig. 5).

Polarized light microscopy showed that both the cellular infiltration in the septa and in the fibrotic areas large numbers of birefringent inclif sions were present. These consisted mainly of lofig fine fibres, frequently forming bundles (Fig. Because the patient was exposed to several fibfos identification of the inclusions was attemptef. The presence of polyester was confirmed by the techniques described above.

CASE 4 A 31-year-old housewife had work $\stackrel{\overrightarrow{\mathbb{Q}}}{\mathrm{Q}}$ four years previously in a factory manufacturimg clothes from synthetic fibres. Eight months after 


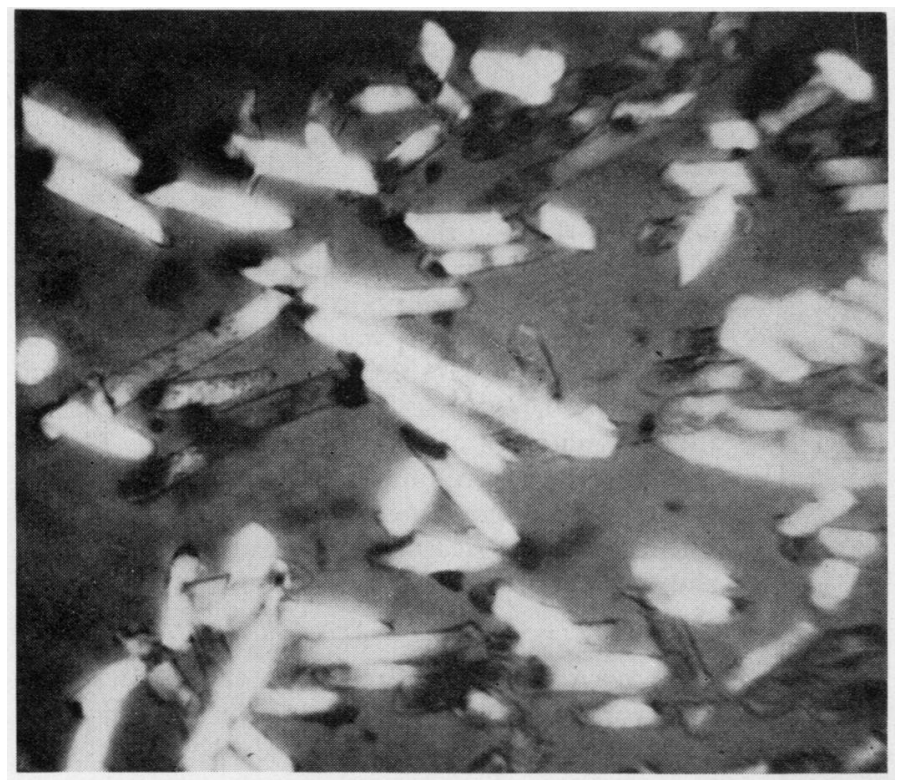

FIG. 4. Case 2. Sample of polyester fibres (Terylene). Polarized light ( $\mathrm{H}$ and $E \times 250)$.

FIG. 5. Case 3. General view of lung lesions. Marked diffuse fibrosis, mainly under the pleura, and honeycombing ( $H$ and $E \times 25)$.

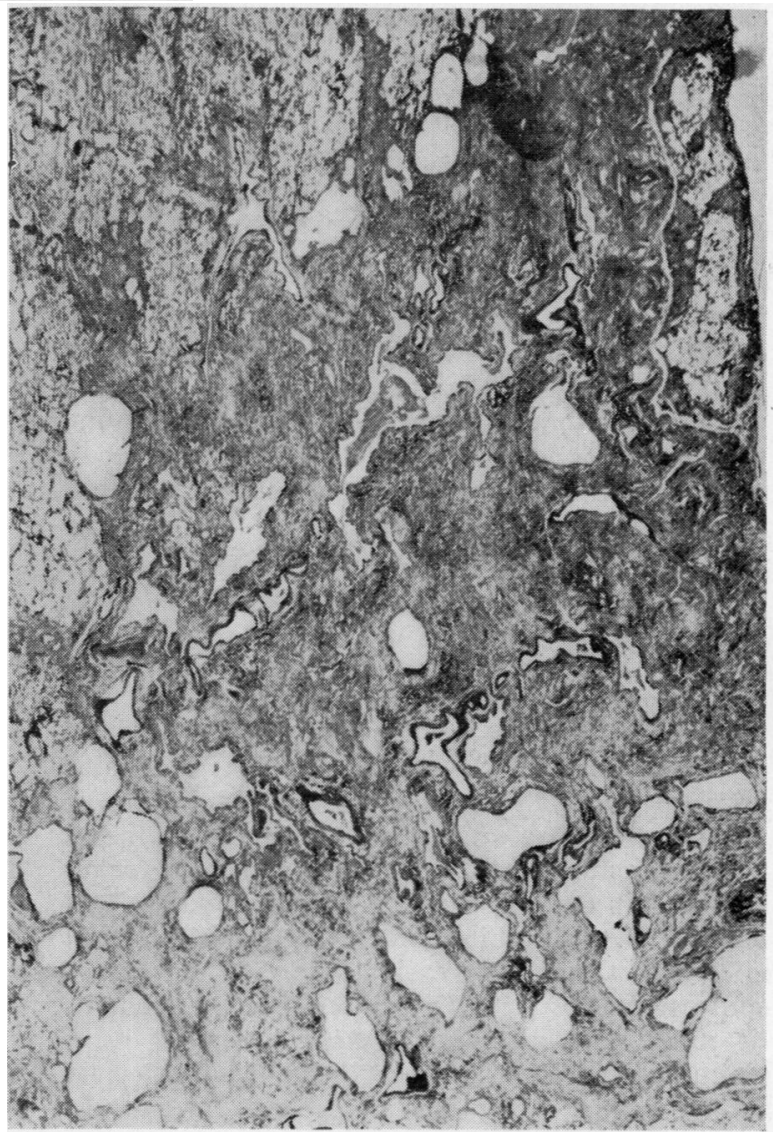




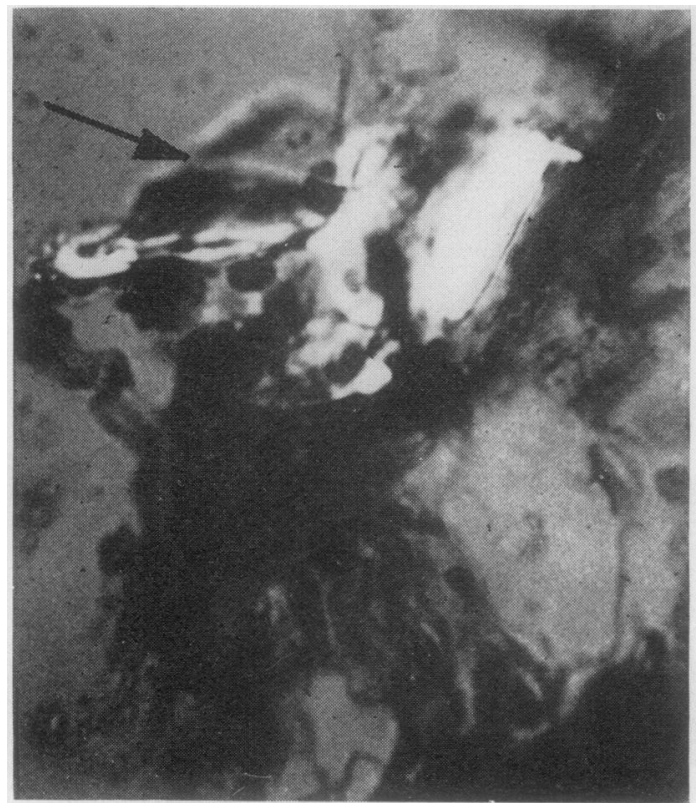

FIG. 6. Case 3. Detail of an area of fibrosis (polarized light). Abundant birefringent inclusions correspond to acrylic fibres (arrow) ( $H$ and $E \times 550)$.

starting work she became pregnant, and breathlessness on exertion set in. After delivery she did not return to the factory because she tired easily. For two months her breathlessness had become progressively worse until it was constant. Auscultation showed crackles over both lung fields. A chest radiograph showed markedly increased lung markings. A haemogram, proteinogram, and sedimentation rate were within normal limits. Respiratory function tests showed a restrictive ventilatory defect with normoxaemia and hypocapnia. The transfer factor was reduced. Transbronchial lung biopsy showed focal lesions in the lung with thickening of the interalveolar septa and partially or completely obliterated alveolar structure. The thickening was due to a proliferation of histiocytes and fibroblasts, reticulin, and often collagen fibres. Some hyalinization was seen. Inclusions of a fibrillar material made up of long thin filaments with haematoxylin affinity were disposed irregularly within the lesions (Fig. 7) or in bundles. This material was not birefringent on polarized light microscopy but was easily identified on phase contrast microscopy. The patient had worked for 17 months in a factory where 'woollies' were manufactured from an acrylic material (Crylor) and her first symptoms appeared after eight months' exposure. The process of manufacture of the articles produced a very fine dust that aftef? a while gave the patient a sensation of oppression in the chest and breathlessness. Chemical study of. samples of the 'wools' and the dust from the patient's environment confirmed the presence ob acrylic fibres, and the inclusions in the pulmonares lesions had the same characteristics. In some areasthe inclusions stained poorly, were wavy, and had irregular calibres. This was particularly evident in areas with considerable collagen formation, and this may correspond to chemical changes in the्र inhaled material, as seems to be shown by the dew position of fine granulations of calcium along the fibres. Three months after discharge breathlessi ness progressed steadily and the chest radiograplp showed a marked increase in the fibrotic lesions?

CASE 5 A 54-year-old male factory worker, whơ had worked for the last 10 years in a factory that produced nylon materials, in March 1960 began to complain of persistent cough productive of large amounts of sputum, sneezing, and rhinoro rhoea. These symptoms appeared exclusivel se during working hours and disappeared when ho left the factory environment. Despite various antio biotic treatments the symptoms never disappeare $\$$ completely. In October 1964, after a bout of 'influ $\vec{\circ}$ enza', persistent cough returned together witls breathlessness on exertion, mucopurulent sputum? and some blood streaking. Since March $1965_{2}^{\circ}$. small repeated haemoptyses occurred for which he was admitted to hospital. A chest radiograple showed a considerable increase in lung marking in the right lower lobe with enlarged dense hilas Bronchoscopy showed no changes. Bronchograph showed diffuse saccular bronchiectasis in the righ lower lobe. A haemogram and sedimentation rate were normal. Right lower lobectomy was per? formed. Macroscopic examination of the remove $\phi$ lobe confirmed the presence of bronchiectasis an showed extensive interstitial fibrosis, especially around the bronchi. The walls of the dilatee bronchi were infiltrated with lymphocytes, plasmo cells, and neutrophils, and the fibrosis that enve loped them was made up of conglomerated cicav tricial nodules (Fig. 8), some of which stilb contained appreciable numbers of histiocytes an $\overline{\mathrm{D}}$ fibroblasts grouped into granulomata. Polarize light microscopy showed numerous birefringento inclusions, both isolated and in bundles made up of fine, elongated fibres or of fine particles of varied morphology disposed within the lesions $\widetilde{\mathbb{Q}}$ The hilar lymph nodes showed lesions of sinus 


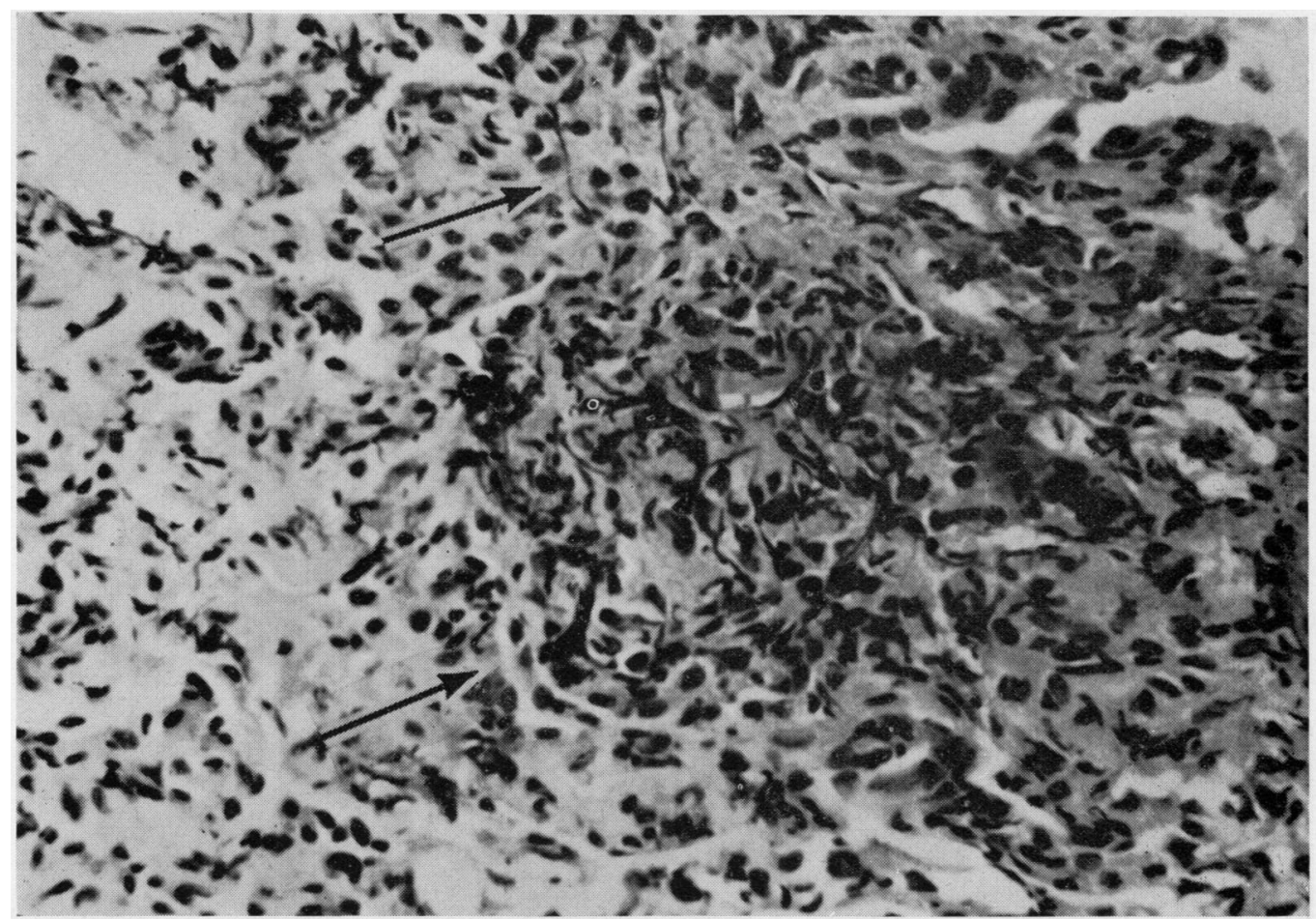

FIG. 7. Case 4. Thickening of the interalveolar septa with obliterated alveolar structure. Abundant inclusions of a fibrillar material made up of acrylic fibres $(H$ and $E \times 125)$.

histiocytosis, and polarized light showed numerous birefringent particles, similar to those described, in the histiocytes found within the sinuses. The fibres manipulated by the patient and the dust from the factory environment were proved to contain nylon fibres (Fig. 9) and the birefringent inclusion found in the lesions in the lungs also contained nylon (Fig. 10). The patient has continued to work in the same job. His symptoms improved after operation but over the past year progressive breathlessness has set in. A chest radiograph shows diffuse, bilateral, reticulonodular infiltrations and pulmonary function tests show a restrictive defect.

CASE 6 A 27-year-old male factory worker, who since the age of 21 had worked as a mechanical weaver manipulating carded wool and polyester fibres, in May 1971 developed a spontaneous pneumothorax on the right side for which he was admitted to hospital. Intercostal tube drainage was instituted and complete expansion of the lung resulted. In August 1971 he was again admitted with another spontaneous pneumothorax on the right side. For the past year he had complained of bouts of cough and sputum and a chest radiograph showed pneumothorax and an emphysematous bleb in the right upper lobe. Thoracotomy was performed and a group of emphysematous bullae about the size of a tangerine were seen, with no other visible lesions in the lung. A resection of the emphysematous area was performed. Histology of the surgical specimen showed that both the visceral pleura and the neighbouring interalveolar septa were thickened and fibrotic and that the walls of the bullae contained numerous inclusions of a fibrillar material made up of fine short filaments that in routine stains were yellowish and showed strong birefringence with polarized light. (Fig. 11).

The high birefringence of the material included in the lung lesions, very similar to that of 


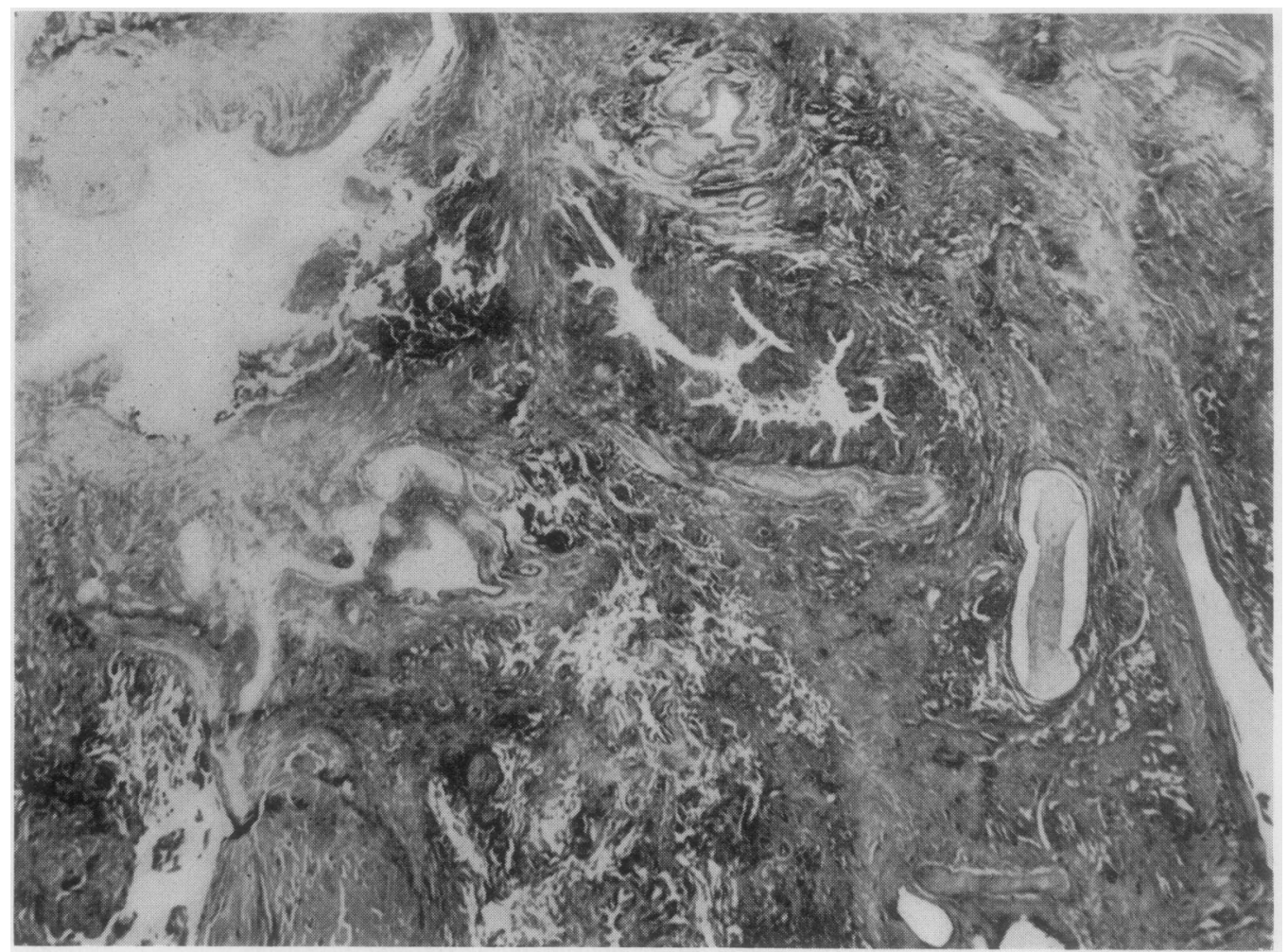

FIG. 8. Case 5. General view of lung lesions. Bronchiectasis. Extensive interstitial fibrosis, especially around the bronchi $(H$ and $E \times 35)$.

the samples of polyester, led us to suspect that this synthetic material was involved, and this was confirmed by solubility and staining reactions. Although this patient continued to work in the factory, he was placed in a position where exposure to the synthetic material was minimal. Since his operation in August 1971 he has had no complaints.

CASE 7 A 46-year-old male textile worker, who since the age of 22 had worked with wool, cotton, and nylon, began to have pain in the right chest with cough, mucopurulent sputum, and some blood streaking. A chest radiograph showed a tumour-like shadow in the right hilum. A chest radiograph on admission (17 April 1969) showed a right hilar mass with poorly defined borders. Bronchoscopy was negative and no malignant cells were found either in the sputum or in the bron- chial aspirate. A haemogram and sedimentation rate were normal. Ventilatory tests showed of restrictive defect. While preparing the patient for surgery a marked spontaneous regression of the lesion was noted. Surgery was postponed and the patient was maintained under observation. A chese radiograph on 4 October 1969 showed practically no change. At operation no tumour was found in the lung but enlarged hilar glands were seen. Two interlobar glands were removed and a biopsy was $\omega$ taken from the lung. Histology showed irregularly? thickened interalveolar septa due to oedema ande infiltration with histiocytes, fibroblasts, and reticu-\$ lar fibres. Peribronchial lymphohistiocytic infiltra-tions and a slight thickening of the pleura were $\frac{0}{T}$ also noted. Polarized light microscopy showed

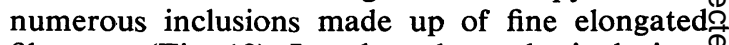
filaments (Fig. 12). In other places the inclusions@ were irregular, rectangular or needle-like in close 


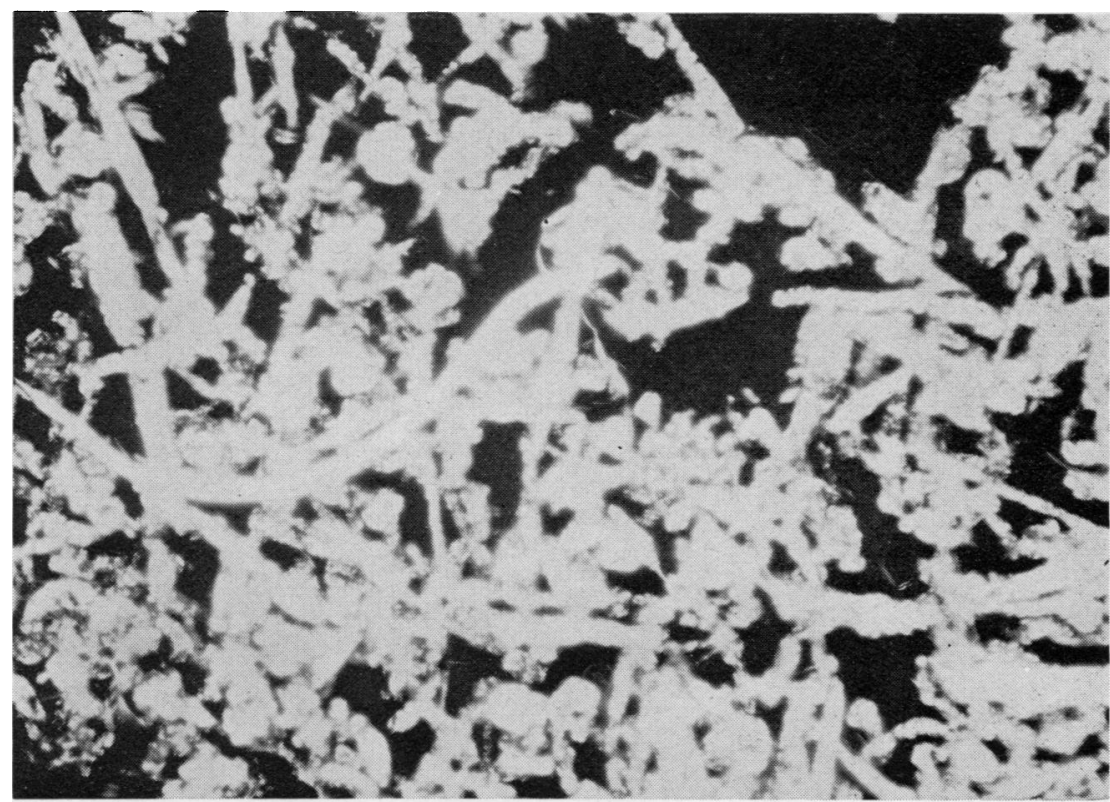

FIG. 9. Case 5. Paraffin section of a sample of nylon fibres. Polarized light $(H$ and $E \times 30)$.

relation to the septal lesions. The lymph nodes showed diffuse lymphoreticular hyperplasia containing large amounts of a similar material to that found in the lungs. Physical and chemical studies of the foreign material in the lung biopsies showed by its birefringence and solubility reactions that it was nylon. This patient continues in his job although he says he is 'careful'. He complains of bouts of coughing, mucoid sputum, and slight breathlessness. A chest radiograph one year after lung biopsy showed increased lung markings, and lung function tests were similar to those performed during his stay in hospital.

\section{IMMUNOLOGICAL STUDIES}

The wool antigens obtained were insoluble in normal saline and could not therefore be used in double diffusion techniques.

Circulating precipitins could be demonstrated in the serum of two patients and 25 blood donors when tested with polyester antigens extracted with Coca fiuid. No precipitation arcs were detected when antigens extracted with Coca fluid from nylon and a polyester and wool mixture were used.
No precipitins were obtained by Culliford's electrophoresis technique, although the products migrated perfectly in the medium.

Skin and nasal sensitivity tests were also negative for all antigens.

\section{EXPERIMENTAL STUDIES}

Lesions were found in the lungs of 14 guinea-pigs exposed to nylon dust and in 10 exposed to Orlon dust. All these lesions were found in the animals sacrificed at the end of the experiment except in one that died unaccountably at $\mathbf{2 1 0}$ days. Only in one case were there abnormal radiographic findings. All, however, were visible macroscopically as small subpleural, red or yellow foci surrounded by small areas of emphysema. Microscopy showed the nodular aspect of the lesion (Fig. 13) and the tendency to conglomerate, forming large foci within which emphysematous alveoli may remain.

The lesions were localized in the interalveolar septa and consisted of oedema, reticular fibres, and, especially, granulomatous cellular proliferations made up of histiocytes and fibroblasts. There was no appreciable difference between the lesions 


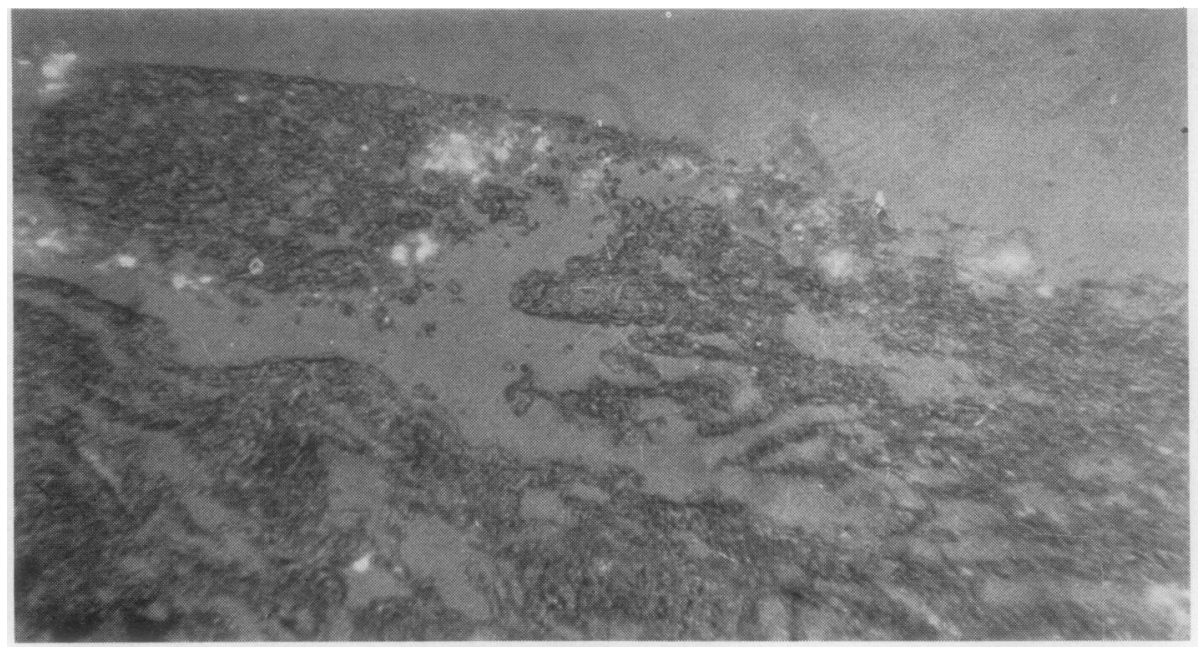

(a)

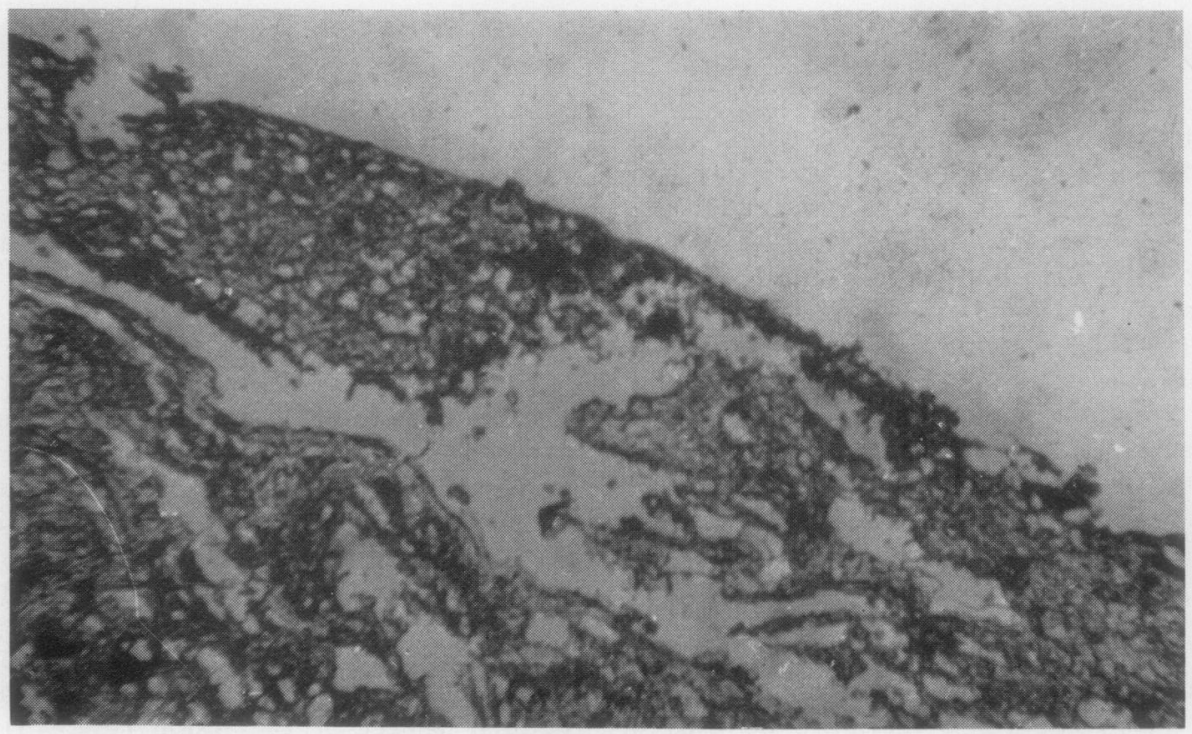

(b)

FIG. 10. Case 5. (a) View of a zone of pulmonary lesions. Birefringent inclusions of nylon (polarized light) ( $H$ and $E \times 15)$. (b) Same area as in (a) after addition of $m$-cresol. Note total solution of the nylon fibres. 


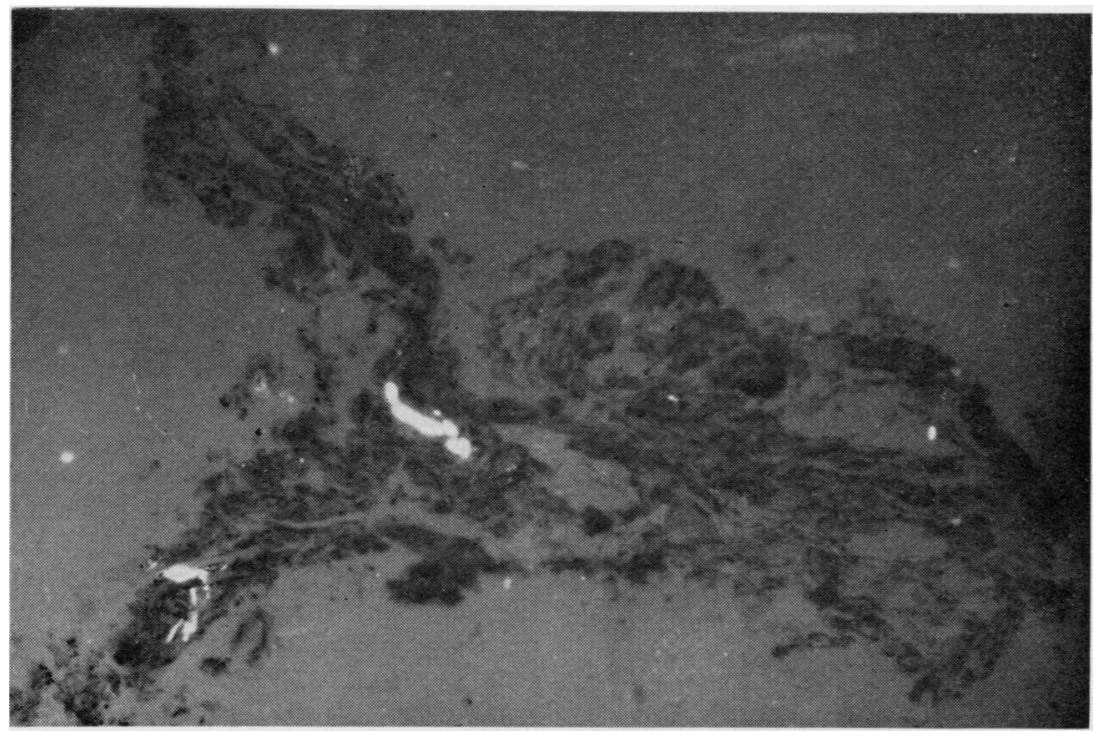

FIG. 11. Case 6. View of the lung lesions. Numerous inclusions of polyester fibres (polarized light) $(H$ and $E \times 75)$.

produced by nylon or Orlon dust. In all cases it was possible to identify the particles of the inhaled material within the lesions by the methods described.

\section{DISCUSSION}

The data presented seem to show that workers in the textile industry manipulating synthetic fibres and those who make clothes from them may be subject to pathological changes in the respiratory tract directly related to the inhalation of their dust.

These may present clinically as asthma-like syndromes, interstitial disease of the lungs similar to extrinsic allergic alveolitis, chronic bronchitis with bronchiectasis, spontaneous pneumothorax or lung shadows impossible to distinguish from lung cancer.

Case 1 is an example of an 'asthma-like syndrome' in a weaver who worked with acrylic fibres. Her symptoms were those usually found in asthma, and the most representative morphological changes were cellular infiltration of the bronchial wall with numerous eosinophils and granulomatous proliferations of histiocytes containing intracellular inclusions of acrylic fibres both in the bronchial mucosa and in the lung tissue obtained by biopsy.

This may be the pathological expression of an immediate bronchial reaction to inhalation of the synthetic material. The fact that other similar diseases - maple bark disease (Towey, Sweany, and Huron, 1932), bird fancier's lung (Carrego,1969), and suberosis (Pimentel and Avila, 1973)-may present asthma-like manifestations and that we identified another 'aggressor'-cork dust-in the bronchial mucosa of cork workers with asthmalike syndromes seems to support this theory. However, other factors may be responsible for the onset of bronchial asthma in workers in the textile industry, as, for instance, phthalic anhydride used in the production of nylon (Simonin, 1961).

Cases 2,3 , and 4 present clinical and radiological features very similar to those of extrinsic allergic alveolitis. Case 2 shows an insidious form of the disease whose radiographic changes regressed partially, as usually happens soon after the patient is removed from specific exposure. The lesions in this case had a focal distribution, predominantly in the alveolar septa. Case 3 may be an example of a chronic from of disease, in a terminal phase, characterized clinically by progressive respiratory 


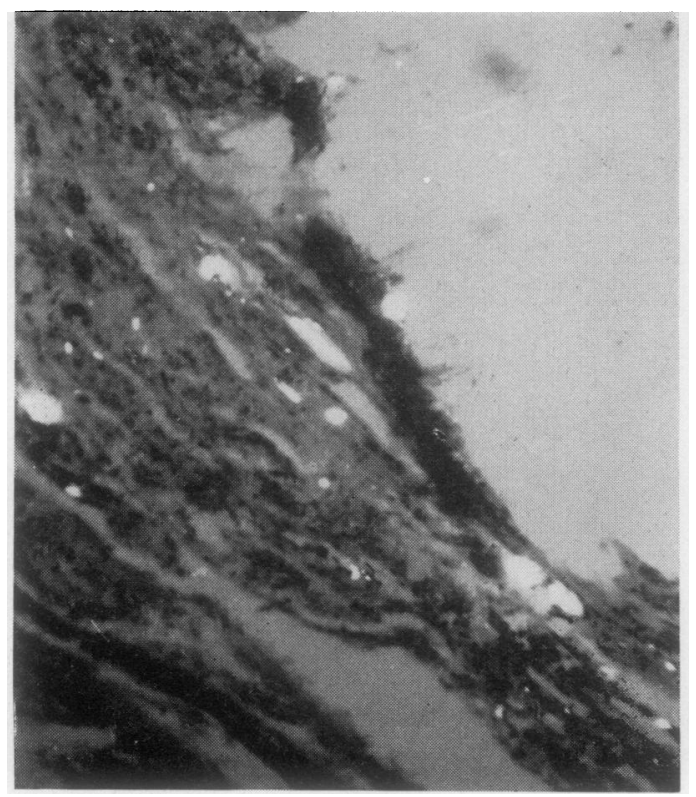

FIG. 12. Case 7. Polarized light microscopy shows numerous birefringent inclusions corresponding to nylon fibres ( $H$ and $E \times 35)$.

insufficiency and pathologically by diffuse interstitial fibrosis with inclusions of the synthetic material, sometimes in granulomata together with emphysema and honeycombing. This chronic form of the disease was preceded, as frequently happens in extrinsic allergic alveolitis, by an acute phase running an insidious course, manifested by bouts of coughing, mucoid sputum, and weakness that probably went on for years.

Case 4 appears to be a chronic form of extrinsic allergic alveolitis that differs from the previous case by the apparent lack of an initial acute phase and by its highly progressive course. In this case, although the lesions showed considerable deposition of collagen, as in the chronic forms, they were still highly cellular, probably related to the rapidly progressive course of the process.

However, in cases 2, 3, and 4 it has not been possible to demonstrate some aspects that have been considered important for the definition of the concept of extrinsic allergic alveolitis. We have no immunological support for the idea nor have we found any epithelioid, sarcoid-type granulomata in these patients. However, sarcoid granuloma is not a compulsory feature of extrinsic allergic alveolitis, and some cases of this type of disease found in cork workers present pathological features very similar to those found in cases 3, and 4 (Pimentel and Avila, 1973).

Case 5 may constitute a form of the disease whose manifestations are predominantly centre on the bronchial tree and whose clinical expressio 7 is comparable to chronic bronchitis. Its course was marked by progressive severity of the initial symptoms and, later, by haemoptysis and suppuration. Radiology, including bronchography, demonstrated bronchiectasis localized to a singtes lobe. Lobectomy led to considerable symptomati improvement, but later the course of the disease progressed slowly towards respiratory insufficis ency. Pathological changes in the lung were of ain inflammatory and fibrotic character, involvinigg predominantly the bronchi, the peribronchovas cular connective tissue, and the neighbouring af veolar walls. Here extensive granulomatous lesions, both recent and cicatricial, were related the presence of inclusions of the inhaled nylow dust. We have observed manifestations of chronit bronchitis with bronchiectasis in workers in the cork industry (Pimentel and Avila, 1973). In these cases cork was identified in exactly the same ares as those in which polyester particles were found $\frac{\mathrm{m}}{\overline{\mathrm{m}}}$ case 5.

Finally, cases 6 and 7 are apparently localize forms of the disease, one presenting as spontaneous pneumothorax and the other as a segmenta consolidation, radiologically simulating lung cancer. Case 6 is comparable to some cases of spontaneous pneumothorax reported in other occupational lung diseases-coal miner's pnew moconiosis, silicosis, berylliosis, aluminosis, an 'bauxite lung' (Crofton and Douglas, 1969). This increases the resemblance between these cond tions and may allow us to postulate a certain re lationship between bullous emphysema and the inhalation of synthetic fibres. The extension of the lesions to the interalveolar septa and the large numbers of polyester particles within granulomas ous histiocytic formations around the emphyse matous areas seem to support this view.

Case 7 should be interpreted as a tumour-like chronic pneumonia, and the suspicion of a rel\$ tionship between the inhalation of nylon fibres and the genesis of the condition should lead to furthe investigations of other such cases of chronic pneq monia. The morphological changes in the lesiond in this case were very similar to those seen in the inital phases of 'extrinsic allergic alveolitis' 0 alveolar oedema and predominantly histiocytic io filtration of the septa. This makes understandabe the radiological regression after the patient w星 removed from the factory environment.

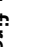


Although all the cases reported seem to have special characteristics, they are probably not distinct entities. The basic pathological patterns are the same although their distribution varied. They either have a diffuse interstitial distribution (cases 2,3 , and 4), are localized, seeming to have a greater affinity for the peribronchial regions (case 7), or seem particularly to involve the subpleural areas (case 6). On the other hand, in predominantly 'bronchial' forms of the disease (cases 1 and 5), granulomatous lesions were found in the lung tissue, similar to those seen in the 'alveolar' forms.

The different manifestations of bronchopulmonary disease due to inhaled particles probably depend partly on the dose and concentration of the substance to which the patient is exposed (Villar, 1968). The simultaneous presence of 'bronchial' and 'interstitial' lesions in the same patient makes it understandable why some patients respond to the inhalation of foreign particles with manifesta- tions similar to bronchial asthma, and others with those of extrinsic allergic alveolitis, as in hypersensitivity to the enzymes of Bacillus subtilis (Pepys et al., 1969), and workers in the cork industry (Pimentel and Avila, 1973).

Because of the similarity of the pathological findings in the patients studied and in other diseases of this type, especially suberosis, we turned to immunology to try to obtain a diagnostic method that would dispense with lung biopsy. It was however impossible to use antigens produced from wool as it was impossible to obtain solutions with a suitable $\mathrm{pH}$ for immunochemical techniques. In the workers studied this material does not seem to be pathogenic. When nylon, polyester, and polyester and wool antigens were tested against the sera of patients and controls by agar double diffusion techniques, only polyester antigens produced precipitins, and these were not specific as they appeared in both the patients and

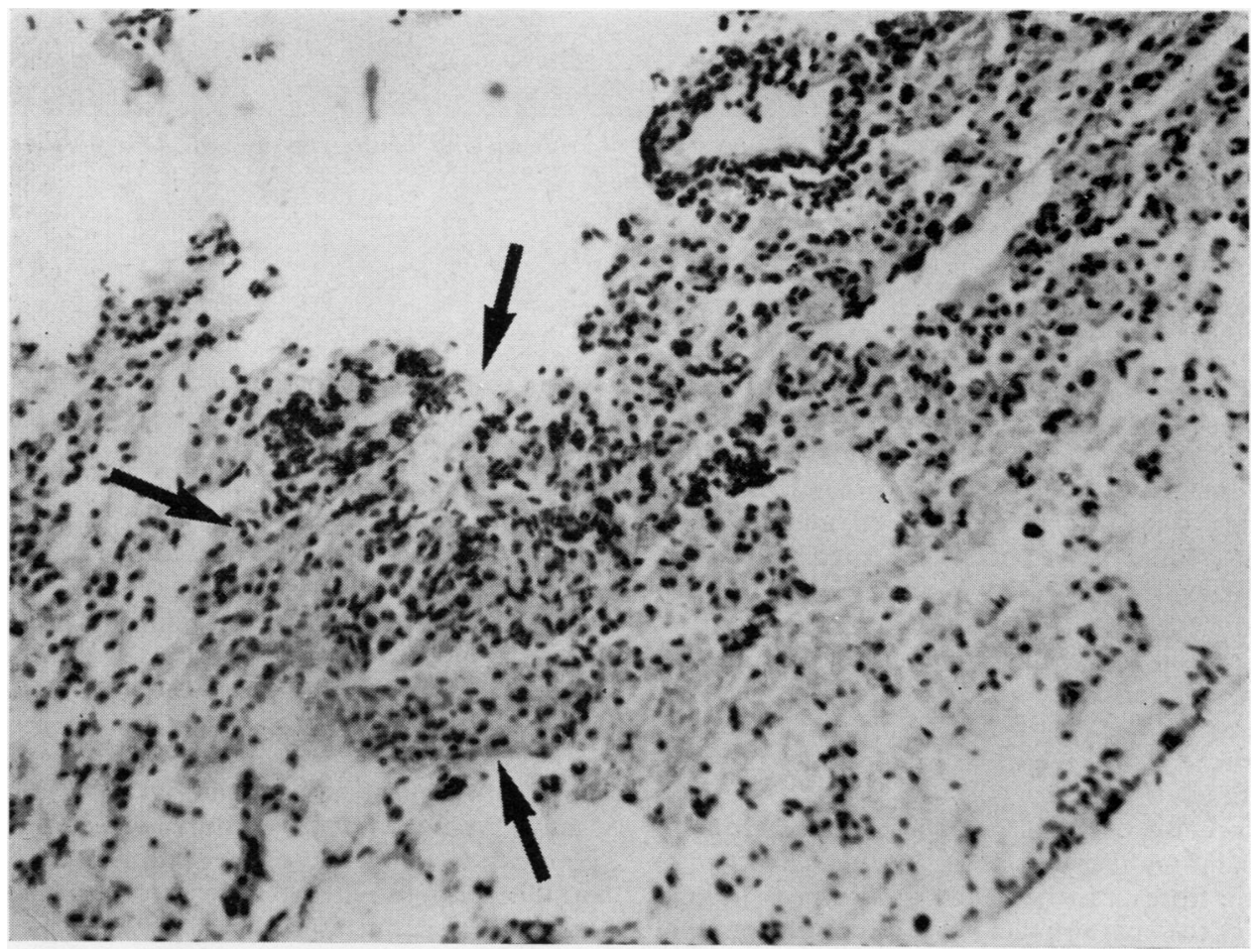

FIG. 13. (a) Lung of a guinea-pig exposed to Orlon dust for 324 days. Nodular lesions of the interalveolar septa made up of histiocytes, fibroblasts, and oedema $(H$ and $E \times 45)$. 


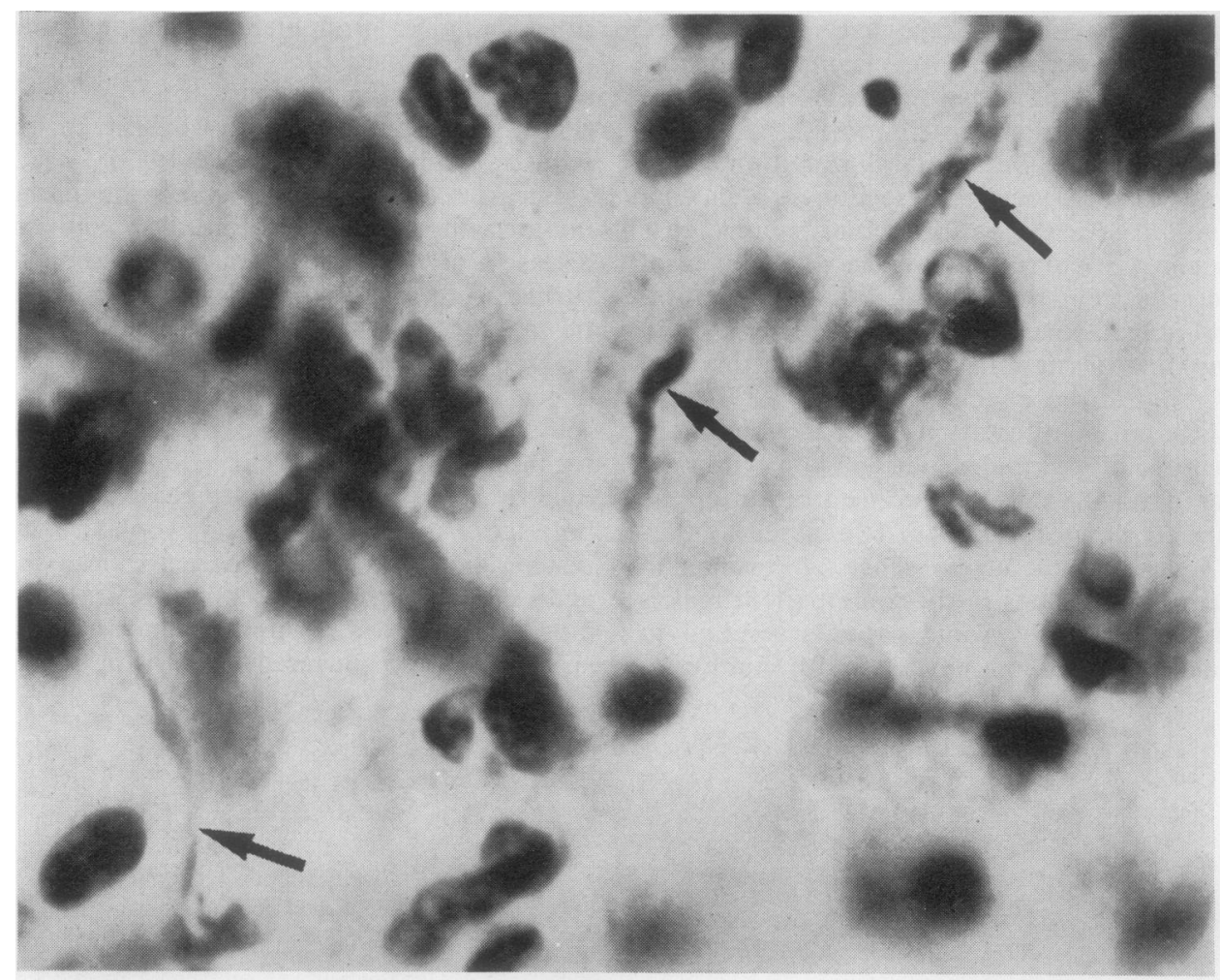

FIG. 13. (b) Detail of (a). Note the presence of oedema and histiocytes as well as a fibrillar material made up of Orlon fibres (arrows) ( $H$ and $E \times 495)$.

the controls. Culliford's technique, frequently used in forensic medicine, showed no advantages over double diffusion. The fact that we got no response to skin sensitivity tests is not surprising. As prick tests were done, only type I (Gell and Coombs) reactions could have been expected and these would probably be absent in these cases. We also found no positive reactions in approximately $\mathbf{4 0}$ cases exposed to synthetic materials studied with Bencard antigens. For the same reason the negative nasal provocation tests using suspensions of ultrasonically disintegrated material in olive oil are justified.

The precise diagnosis of the various bronchopulmonary manifestations in workers exposed to synthetic fibres can be made at the present time only by the pathological examination of lung tissue obtained by needle or surgical biopsy. Because of the non-specific nature of the lesions when routine histological techniques are used, is necessary to undertake a precise characteriza tion of the inhaled synthetic material, in botk recent and cicatricial lesions.

The marked resemblance between the lesions obtained experimentally in animals and those. found in man is notable, including the initiaf focal distribution, their extension by conglomeration of initially isolated lesions, and the histog chemical characterization of the inhaled materials within the lesions.

The clinical course of the patients reported shows that prognosis is usually favourable in the 'acute type' or recently established lesions but is poor when irreversible interstitial fibrosis has se in. The patients in the latter group have signs of progressive respiratory insufficiency.

It is probable that this condition is an occup $\frac{\vec{Q}}{2}$ tional disease of inhalatory origin set off by ap 
individual factor, and in which many mechanisms are involved. One is the presence of the dust of the synthetic fibres in the lung and the other is probably of an immunological nature. This seems to be shown by the fact that one of the manifestations of the disease mimics extrinsic allergic alveolitis similar to those observed in other diseases where immunological studies of undoubted practical value have been carried out.

\section{REFERENCES}

Abe, A. and Ishikawa, T. (1967). Studies on pneumoconiosis caused by organic dusts. Journal of the Science of Labour, 43, 19.

Algerino, A. (1969). Riconoscimento e Dosaggio delle Fibre Tessili e Controlli di Lavorazione, edited by Laniera. Biella, Vicenza.

Avila, R. (1968). Immunological study of pulmonary aspergilloma. Thorax, 23, 144.

Carrego, M. C. (1969). Mesa redonda sobre pulmão imunológico IV-Estudos laboratoriais. Jornal da Sociedade das Ciencias Médicas de Lisboa.

Crofton, J. and Douglas, A. (1969). Respiratory Diseases. Blackwell Scientific Publications, Oxford and Edinburgh.

Culliford, B. J. (1964). Precipitin reactions in forensic problems. Nature, 201, 1092.

Goddard, D. R. and Michaelis, L. (1934). A study on keratin. Journal of Biological Chemistry, 106, 605.

Koch, P. (1963). Microscopic and Chemical Testing of Textiles. Chapman and Hall, London.
Pearse, A. G. E. (1968). Histochemistry: Theorectical and Applied, 3rd edition. Churchill, Edinburgh.

Pepys, J., Hargreave F. E., Longbottom, J. L., and Faux, J. (1969). Allergic reactions of the lungs to enzymes of Bacillus subtilis. Lancet, 1, 1181.

Pimentel, J. C. and Avila, R. (1973). Respiratory disease in cork workers ('suberosis'). Thorax, 28, 409.

Sano, T. (1967). Pathology and pathogenesis of organic dust pneumoconiosis. Journal of the Science of Labour, 43, 3.

Simonin, C. (1961). Pathologie professionnelle dans l'industrie des fibres artificielles. Médecine du Travail, Paris.

The Textile Institute (1970). Identification of Textile Materials. Tinling, London.

Tiller, J. R. and Schilling, R. S. F. (1958). Respiratory function during the day in rayon workers: a study in byssinosis. Transactions of the Association of Industrial Medical Officers, 7, 161.

Towey, J. W., Sweany, H. C., and Huron, W. H. (1932). Severe bronchial asthma apparently due to fungus spores found in maple bark. Journal of the American Medical Association, 99, 453.

Villar, T. G. (1968). Mesa redonda sobre 'pulmão imunológico'. I. Introdução. Jornal da Sociedade das Ciencias Médicas de Lisboa, 133, 457.

Requests for reprints to: Professor J. C. Pimentel, Instituto de Anatomia Patológica, Hospital de Santa Maria, Lisbon, Portugal. 